\title{
Developing of scientific resources for marker-assisted selection of a new legume crop - Cyamopsis tetragonoloba (L.) Taub. as a base for guar gum industry in Russia
}

\author{
Potokina E.K. ${ }^{1,2 *}$, Ulianich P.S. ${ }^{1}$, Grigoreva E.A. ${ }^{1}$, Volkov V.A. ${ }^{1}$ \\ ${ }^{1}$ N.I. Vavilov All-Russian Institute of Plant Genetic Resources (VIR), St. Petersburg, Russia \\ ${ }^{2}$ St. Petersburg State University, St. Petersburg, Russia \\ *e-mail: e.potokina@vir.nw.ru
}

Since Sept. 2017 Vavilov Institute has been leading the national project focusing on the development of new varieties of guar using marker-assisted selection for import substitution of guar gum for the oil, gas and food industries in Russia. Guar, an herbaceous legume plant, is widely cultivated in India, Pakistan, Afghanistan, Kenya, Australia, and semi-desert regions of the United States. Guar gum, extracted from the seeds of guar, is in demand in the oil and gas industry. Until now, guar gum has been fully exported from abroad. Nowadays, there is an evident need to develop new guar varieties, adapted to the conditions of cultivation in the territory of the Russian Federation. In frame of the project various approaches of modern breeding were employed. Among them are ecological testing of a number of genotypes in different climatic conditions, field evaluation of VIR guar germplasm collection in Kuban experimental station (Krasnodar area), high throughput genotyping of the diversity panel of $\sim 200$ genotypes by RADseq method using Illumina HiSeq2500 and Genome-Wide Association Study. Since guar is a short-day plant, a special effort was made to discover the photoperiod insensitive genotypes among the guar genetic diversity tested. Valuable genotypes with the shortened vegetation period were discovered. Original laboratory methods have been developed for estimating the percentage and viscosity of gum in guar seeds. Root nodule bacteria were isolated from guar, their 16S rRNA sequences were deposited in NCBI. As the result, five most promising breeding lines were suggested as the new guar varieties adopted to the climate conditions of Krasnodar region. Astrakhan and Volgograd regions are suggested as the regions where the new crop can be successfully propagated under irrigation.

Acknowledgements: The study was supported by the Ministry of Science and Education of the Russian Federation (Project RFMEFI60417X0168, Agreement No. 14.604.21.0168). 